\title{
HUBUNGAN KECANDUAN BERMAIN GAME ONLINE DENGAN MOTIVASI BELAJAR PADA SISWA SMP DI KOTA BANDAR LAMPUNG TAHUN 2019
}

\author{
Elizabeth Theresia ,Octa Reni Setiawati ${ }^{2}$, Ni Putu Sudiadnyani ${ }^{3}$ \\ ${ }^{13}$ Fakultas Kedokteran Universitas Malahayati, ${ }^{2}$ Program Studi Psikologi \\ Universitas Malahayati \\ ores.survive@gmail.com
}

\begin{abstract}
The development of internet technology is very rapid throughout the world today, including in Indonesia. One of the fastest growing internet technologies is online gaming. Ideally a student is more concerned with school rather than playing online games, but in reality, there are still many students who are more concerned with playing online games rather than schools, resulted that these students have low learning motivation. Knowing the relationship between addictions to playing online games with learning motivation in junior high school students in Bandar Lampung City. This study is an analytical study with cross sectional approach, the sampling method used in this study is the random sampling of all junior high school students in Bandar Lampung City. The data used in this study was a primary data with an addiction questionnaire of playing online games \& learning motivation questionnaires. Bivariate analysis used the Spearman Rank test. The number of respondents was 546 students. Univariate test showed for the level of addiction to playing online games with a median (minimum-maximum) value of 56 (21-105) and for learning motivation level with a median value (minimum-maximum) of 129 (57-177). The bivariate test results of the correlation analysis obtained $\mathrm{p}=0.000$ and the value $\mathrm{r}=-0.999$. There is a significant relationship that is not in a same direction with the strength of a very strong correlation between addiction to playing online games with motivation to study in junior high school students in the city of Bandar Lampung in 2019.
\end{abstract}

Keywords: Addiction to online games, Learning Motivation

\begin{abstract}
ABSTRAK
Perkembangan teknologi internet termasuk di Indonesia sangat pesat. Salah satu dari teknologi internet yang berkembang sangat pesat adalah game online. Idealnya seorang siswa lebih mementingkan sekolah daripada bermain game online, tetapi pada kenyataannya masih banyak siswa yang lebih mementingkan bermain game online daripada sekolah, sehingga siswa tersebut memiliki motivasi belajar yang rendah. Mengetahui hubungan antara kecanduan bermain game online dengan motivasi belajar pada siswa SMP di Kota Bandar lampung. Jenis penelitian ini adalah analitik pendekatan cross sectional, pengolahan metode sampel dengan random sampling seluruh siswa SMP se-Kota Bandar Lampung. Pengambilan data menggunakan kuesioner kecanduan bermain game online\& kuesioner motivasi belajar. Analisis bivariat dengan uji Rank Spearman's. Jumlah responden 546 siswa diketahui hasil uji univariat tingkat kecanduan bermain game online dengan nilai median (minimum-maksimum) yaitu 56 (21-105), tingkat motivasi belajar dengan nilai median (minimummaksimum) yaitu 129 (57-177). Hasil uji bivariat analisis korelasi didapatkan nilai $p=0.000$ dan nilai $r=-0.999$. Terdapat hubungan bermakna yang tidak searah dengan kekuatan korelasi sangat kuat antara kecanduan bermain game online dengan motivasi belajar pada siswa SMP di kota Bandar Lampung tahun 2019.
\end{abstract}

Kata Kunci:Kecanduan bermain game online, Motivasi belajar 


\section{PENDAHULUAN}

Perkembangan teknologi internet termasuk di Indonesia sangat pesat. Teknologi internet memberikan manfaat yang sangat besar bagi kemajuan di segala bidang kehidupan. Salah satu dari teknologi internet yang berkembang sangat pesat adalah game online (Ismail, 2016). Menurut hasil survey tahun 2017 oleh Asosiasi Penyelenggara Jasa Internet Indonesia, jumlah pengguna internet di Indonesia dari total populasi penduduk Indonesia 262 juta juta orang ialah 54,68\% atau 143,25 juta jiwa. Sebanyak $87,13 \%$ mengakses social media, dan diantaranya yang bermain game sebanyak 54,13\%. (Indonesia, 2017).

Bermain game secara online menggunakan internet digemari banyak kalangan, tidak hanya bagi anak-anak atau remaja, namun juga dewasa awal hingga menjelang lanjut usia (Lutfiwati, 2018). Perilaku anak-anak dan remaja yang memainkan game online ini menyebabkan timbulnya keprihatinan dari para orang tua dan guru, yang menganggap bahwa kebiasaan bermain tadi tersebut berpengaruh buruk pada prestasi akademis dan perilaku sosial mereka (Dewandari, 2013). Idealnya seorang siswa lebih mementingkan sekolah daripada bermain game online agar siswa tersebut memiliki sikap yang positif terhadap sekolahnya. Tetapi pada kenyataannya masih banyak siswa yang lebih mementingkan bermain game online daripada sekolah, sehingga siswa tersebut memiliki motivasi belajar yang rendah (Dewandari, 2013).

Menurut Soleman dampak bermain game online terhadap siswa antara lain, siswa menjadi sulit konsentrasi terhadap sekolah, sering malas bahkan bolos sekolah, menjadi cuek atau acuh tak acuh, tak patuh dan kurang peduli terhadap hal-hal yang terjadi di sekelilingnya. Siswa yang sudah kecanduan akan melakukan apapun agar bisa bermain game online, misalnya berbohong atau mencuri uang. Siswa yang terbiasa hanya berinteraksi satu arah dengan komputer/internet membuat ia menjadi tertutup dan sulit mengeskpresikan diri ketika berada di lingkungan yang nyata (Anhar, 2014). Persentase anak usia sekolah di Indonesia pada tahun 2017 yang mengalami kecanduan bermain game online adalah 10,15\%. Sebagai perbandingan di Korea 2,4\% pada anak usia sekolah dan 10,2\% pada 
rentang usia 9 sampai 39 tahun, di China terdapat 13,7\% sedangkan di Amerika terdapat 1,5\% sampai $8,2 \%$ yang mengalami kecanduan (Jap et al, 2014).

Game online sebagai bagian dari budaya juga berpengaruh terhadap motivasi belajar. Dari hal tersebut dapat kita lihat bahwa, game online yang ada sangat berdampak negatif bagi siswa. Game yang tidak mendidik, sebab gambar-gambarnya hanya fantasi belaka, sehingga sifatnya hanya menyenangkan, dan game hanya membuang-buang uang, waktu, dan membuat seseorang menjadi malas (Marlianti, 2015). Motivasi belajar yang baik akan melahirkan proses dan hasil belajar yang baik tanpa memikirkan hal lain, misalnya bermain game online. Sebaliknya siswa yang motivasi belajar rendah menampakkan keengganan, perhatiannya terpusat pada permainan game online. Oleh karena itu, para guru harus dapat menerapkan proses pembelajaran di kelas yang dapat menumbuh kembangkan motivasi belajar pada diri peserta didik (Hadis dan Nurhayati, 2010).

Dengan adanya hal tersebut yang melatarbelakangi, penelitian ini bertujuan untuk mengetahui apakah ada hubungan kecanduan bermain game online dengan motivasi belajar pada siswa SMP di kota Bandar Lampung tahun 2019.

\section{METODE PENELITIAN}

Penelitian ini menggunakan jenis penelitian kuantitatif dan metode penelitian analitik dengan pendekatan studi potong lintang cross sectional, pada penelitian ini yang ingin di ketahui adalah hubungan kecanduan bermain game online dengan motivasi belajar pada siswa SMP di Kota Bandar Lampung tahun 2019. Populasi merupakan keseluruhan objek penelitian atau objek yang diteliti. Peneliti mengambil sampel siswa SMP pengguna game online yang ada di lingkungan Kota Madya Bandar Lampung tahun 2019, yang berjumlah 21.214 siswa laki-laki terbagi dalam 113 SMP.

\section{HASIL}


Berdasarkan penelitian yang dilakukan dengan menyebarkan kuesioner kecanduan bermain game online dengan motivasi belajar pada siswa SMP di Kota Bandar Lampung pada bulan Desember 2018 - Februari 2019 dengan jumlah 546 responden dari 19 sekolah di setiap kecamatan yang ada di Kota bandar Lampung, didapatkan hasil sebagai berikut:

\section{Tabel 1 Distribusi Frekuensi Karakteristik Responden Berdasarkan Usia Kecanduan} Bermain Game Online Pada Siswa SMP di Kota Bandar Lampung Tahun 2019

\begin{tabular}{ccc}
\hline Usia & Frequency & Persentase $(\%)$ \\
\hline 13 & 293 & 53.7 \\
14 & 216 & 39.6 \\
15 & 32 & 5.9 \\
16 & 5 & 0.9 \\
\hline Total & 546 & 100.0 \\
\hline
\end{tabular}

Berdasarkan hasil data pada tabel 1 distribusi frekuensi karakteristik responden berdasarkan usia kecanduan bermain game online pada siswa SMP di Kota Bandar Lampung tahun 2019. Menunjukkkan bahwa sebagian besar responden yang berusia 13 Tahun sebanyak 293 orang (53.7\%), usia 14 Tahun sebanyak 216 orang (39.6\%), Usia 15 Tahun sebanyak 32 orang (5.9\%), usia 16 Tahun sebanyak 5 orang (9\%).Didapatkan jumlah responden terbanyak siswa berusia 13 Tahun.

Hasil uraian diatas sesuai dengan hasil survey 2017 dalam Asosiasi Penyelenggara Jasa Internet Indonesia bahwa pengguna internet tertinggi berdasarkan usia 13-18 tahun sebesar 75,50\% (Indonesia, 2017). Hasil penelitian ini juga sesuai dengan hasil penelitian yang dilakukan oleh Saputri (2014) pada anak remaja usia 13 tahun sebagai usia tertinggi dalam penggunaan internet dengan persentase $51,5 \%$ dari jumlah total 99 responden. 
Tabel 2 Distribusi Frekuensi Kecanduan Bermain Game Online Pada Siswa SMP di Kota Bandar Lampung Tahun 2019

\begin{tabular}{cccc}
\hline $\begin{array}{c}\text { Tingkat } \\
\text { Kecanduan }\end{array}$ & Frekuensi & Persentase (\%) & $\begin{array}{c}\text { Median } \\
\text { (Minimum-Maksimum) }\end{array}$ \\
\hline Rendah & 113 & 20.7 & \\
Sedang & 270 & 49.5 & $56(21-105)$ \\
Tinggi & 163 & 29.9 & \\
\hline Total & 546 & 100 & \\
\hline
\end{tabular}

Berdasarkan hasil data pada tabel 2 distribusi frekuensi kecanduan bermain game online pada siswa SMP di Kota Bandar Lampung tahun 2019. Menunjukkan bahwa sebagian besar responden mengalami kecanduan sedang sebanyak 270 orang (49.5\%), kecanduan tinggi sebanyak 163 orang (29.9\%), kecanduan rendah sebanyak 113 orang (20.7\%). Didapatkan jumlah responden terbanyak mengalami kecanduan bermain game online tingkat sedang.

Griffiths et al (2004) mengemukakan intensitas bermain game merupakan banyaknya jam (rata-rata) seseorang bermain game setiap minggu. Remaja yang mengalami kecanduan bermain game online pada umumnya menghabiskan waktunya untuk bermain rata-rata 23 jam per minggu (Sophie, 2006). Intensitas tingkat rendah, dikatakan demikian bila remaja bermain game online 1-2 jam dalam sehari, intensitas tingkat sedang bila remaja bermain game online 3-4 jam dalam sehari, sedangkan dikatakan intensitas tingkat tinggi bila remaja bermain game online lebih dari 4 jam sehari. Banyak penelitian melaporkan, pemain game online mengalami kecanduan bermain game online bila remaja tersebut bermain game online lebih dari 4 jam sehari (Young, 2006).

Game Online memerlukan jaringan internet serta beragam jenisnya. Saat pemain memainkan game online, ada rasa senang serta kepuasan secara psikologis. Kepuasan pemain saat memainkan game ini akan membuat pemain semakin tertarik untuk memainkannya (Dewandari, 2013). Kecanduan bermain game online dapat berdampak buruk pada sosial, psikis, ataupun fisik. Secara sosial, hubungan dengan teman bahkan menjadi lebih renggang, pergaulan hanya sebatas di dunia game online sehingga terisolir dari lingkungan sekitar, sulit berkomunikasi dengan orang lain, serta 
perilaku menjadi kasar. Secara psikis, pikiran akan terus menerus memikirkan game online sehingga menjadi sulit untuk berkonsentrasi terhadap studi bahkanbolos dari pelajaran demi bermain game online tersebut. Hal ini juga berpengaruh terhadap motivasi belajar anak tersebut di sekolahnya. Secara fisik, berpengaruh terhadap kondisi kesehatan antara lain merusak saraf mata dan otak akibat terpapar radiasi cahaya (Anhar, 2014).

Dampak dari kecanduan game online ini telah diteliti sebelumnya oleh Ismail (2016), di dalam penelitian nya yaitu fenomena permainan game online Defense of the Ancients (Dota 2) yang merupakan salah satu game online. Dari hasil penelitian didapatkan bahwa para pemain game online ini memiliki tingkat kecanduan yang kuat, terbengkalai kegiatan di dunia nyata yaitu lupa mengerjakan tugas serta prestasi akademik menurun, perubahan pola makan dan istirahat, pemborosan, serta mengganggu kesehatan.

Tabel 3. Distribusi Frekuensi Motivasi Belajar Pada Siswa SMP di Kota Bandar Lampung Tahun 2019

\begin{tabular}{cccc}
\hline $\begin{array}{c}\text { Tingkat } \\
\text { Motivasi Belajar }\end{array}$ & Frekuensi & $\begin{array}{c}\text { Persentase } \\
(\%)\end{array}$ & $\begin{array}{c}\text { Median } \\
\text { (Minimum-Maksimum) }\end{array}$ \\
\hline Rendah & 28 & $5.1 \%$ & \\
Sedang & 275 & $50.4 \%$ & $129(57-177)$ \\
Tinggi & 243 & $44.5 \%$ & \\
\hline Total & 546 & $100 \%$ &
\end{tabular}

Berdasarkan hasil data pada tabel 3 Distribusi Frekuensi Motivasi Belajar pada Siswa SMP di Kota Bandar Lampung Tahun 2019. Menunjukkan bahwa sebagian besar responden yang memiliki motivasi belajar sedang sebanyak 275 orang (50.4\%), motivasi belajar tinggi sebanyak 243 orang (44.5\%), motivasi belajar rendah sebanyak 28 orang (5.1\%).Didapatkan jumlah responden terbanyak dengan motivasi belajar tingkat sedang.

Motivasi belajar adalah keseluruhan daya penggerak di dalam diri siswa yang menimbulkan kegiatan belajar, yang menjamin kelangsungan dari kegiatan belajar dan memberi arah pada kegiatan belajar, sehingga tujuan yang dikehendaki itu dapat tercapai (Sardiman, 2016). Menurut Winkel faktor yang mempengaruhi motivasi belajar salah satunya suasana “jaman modern”, yang mendorong 
untuk bersenang-senang sebanyak mungkin tanpa usaha yang merupakan kegiatan belajar (Dewandari, 2013). Hal ini yang membuat motivasi belajar pada siswa menjadi berkurang karena keinginan siswa hanya untuk bersenang-senang tanpa mempedulikan kewajibannya sebagai siswa, yaitu belajar dan mendapatkan prestasi akademik yang baik di sekolah.

Aspek-aspek motivasi belajar antara lain ketekunan dalam belajar, ulet dalam menghadapi kesulitan, minat dan ketajaman perhatian dalam belajar, berprestasi dalam belajar, dan mandiri dalam belajar (Sardiman, 2016). Oleh sebab itu, siswa dengan aspek-aspek motivasi belajar yang tinggi menunjukkan bahwa siswa tersebut memiliki motivasi belajar yang tinggi, siswa dengan aspek-aspek motivasi belajar tersebut namun belum optimal menunjukkan bahwa siswa tersebut memiliki motivasi belajar yang sedang, dan siswa yang tidak memiliki aspek-aspek motivasi belajar tersebut menunjukkan bahwa siswa tersebut memiliki motivasi belajar yang rendah

Tabel 4. Hubungan Kecanduan Bermain Game Online dengan Motivasi Belajar Pada Siswa SMP di Kota Bandar Lampung Tahun 2019

\begin{tabular}{cc}
\hline & Skor motivasi belajar \\
\hline Skor kecanduan & $\mathrm{r}=-0.999$ \\
& $\mathrm{p}=0.000$ \\
$\mathrm{~N}=546$ \\
\hline
\end{tabular}

Berdasarkan hasil analisis data tabel 4.4 Hubungan Kecanduan Bermain Game Onlinedengan Motivasi Belajar Pada Siswa SMP di Kota Bandar Lampung Tahun 2019. Didapatkan angka koefisien sebesar 0.999 dengan P value $0.000<0.05$ sehingga $\mathrm{P}$ value $<\alpha$ dan Ha diterima. Dapat disimpulkan bahwa ada hubungan yang bermakna antara kecanduan bermain game online dengan motivasi belajar pada siswa SMP di Kota Bandar Lampung tahun 2019. Nilai korelasi $r=-0.999$, artinya kekuatan korelasi sangat kuat dan tanda negatif menunjukkan adanya hubungan yang tidak searah, artinya semakin tinggi tingkat kecanduan bermain game online maka semakin rendah tingkat motivasi belajar, demikian sebaliknya.

Hasil penelitian ini sesuai dengan penelitian serupa sebelumnya oleh Dewandari (2013) yang menyatakan bahwa terdapat hubungan antara intensitas bermain game online dengan motivasi belajar 
pada remaja dimana hasil penelitian ini menunjukkan semakin tinggi intensitas bermain game online maka akan semakin rendah motivasi belajar siswa, begitu juga sebaliknya.

\section{KESIMPULAN DAN SARAN}

Diketahui hubungan kecanduan bermain game online dengan motivasi belajar diperoleh P value $=0.000(\mathrm{P}<0.05)$, artinya terdapat "hubungan bermakna antara kecanduan bermain game online dengan motivasi belajar pada siswa SMP di Kota Bandar Lampung Tahun 2019”. Nilai korelasi r = 0.999, artinya kekuatan korelasi sangat kuat dan tanda negatif menunjukkan adanya hubungan yang tidak searah, artinya semakin tinggi tingkat kecanduan bermain game online maka semakin rendah tingkat motivasi belajar. Demikian sebaliknya, semakin rendah tingkat kecanduan bermain game online maka semakin tinggi tingkat motivasi belajar.

\section{DAFTAR PUSTAKA}

Anhar, R. (2014). Hubungan kecanduan game online dengan keterampilan sosial remaja di 4 game centre di Kecamatan Klojen Kota Malang. Doctoral dissertation, Universitas Islam Negeri Maulana Malik Ibrahim.

Dewandari, S. (2013). Hubungan Antara Intensitas Bermain Game Online Dengan Motivasi Belajar Siswa Kelas X SMK Negeri 1 Sapuran Kabupaten Wonosobo. Doctoral dissertation, Program Studi Bimbingan dan Konseling FKIP-UKSW

Griffiths, M, D., Mark N.O.D. \& Daren Chappell. (2004). Demographic Factors and Playing Variable in Online Computer Gaming. Cyber Pychology ang BehaviorVol 7. No 4.

Hadis, A. \& Nurhayati, B., (2010). Manajemen mutu pendidikan. Bandung: Alfabeta.

Indonesia, A.P.J.I. (2017). Infografis Penetrasi dan Perilaku Pengguna Internet Indonesia. ID: APJII.

Ismail, K.A. (2016). Fenomena permainan game online Defense of the Ancients (Dota 2) pada prestasi akademik mahasiswa perguruan tinggi di Kota Malang. Doctoral dissertation, Universitas Islam Negeri Maulana Malik Ibrahim

Jap, T., Tiatri, S., Jaya, E.S. \& Suteja, M.S. (2013). The development of Indonesian online game addiction questionnaire. PloS one, 8(4), p.e61098.

Lutfiwati, S. (2018). Memahami Kecanduan Game Online Melalui Pendekatan Neurobiologi. ANFUSINA: Journal of Psychology, 1(1), pp.1-16.

Marlianti, D. (2015). Hubungan Kecanduan Bermain Game Online dengan Pola Tidur dan Motivasi Belajar Anak Usia 10-12 Tahun di SD Mattoangin 2 Kecamatan Mariso Kota Makassar Doctoral dissertation, Universitas Islam Negeri Alauddin Makassar

Saputri, O.E., Arifah, S., Kp, S. and Wulaningrum, D.N. (2014). Gambaran Penggunaan Internet Pada Anak Remaja Di SMP Muhammadiyah 1 Kartasura. Doctoral dissertation, Universitas Muhammadiyah Surakarta 
PSYCHE: JURNAL PSIKOLOGI UNIVERSITAS MUHAMMADIYAH LAMPUNG

Sophie, R. (2006). Can you Really be Addiction to a Computer. Online. http://www.netaddiction.com/addiction_to_computer.pdf. Diakses pada tanggal 30 Maret 2019.

Young, K. (2006). Addiction to MMORPGs: Symptom and Treatment Articles. http:www.netaddiction.com/articles/addiction_to_mmorpgs.pdf. Diakses pada tanggal 30 Maret 2019. 